\title{
PENSAMIENTO AMBIENTAL DEL MAESTRO: Ethos-Cuerpo en clave de Bio-Geo-Poéticas del Habitar
}

\author{
TEACHER'S ENVIRONMENTAL THINKING: \\ Ethos-Body in a sense of Bio-Geo-Poetic Inhabiting
}

\author{
Carlos Alberto Chacón Ramírez
}

Licenciatura en Biología y Educación Ambiental, Universidad del Quindío - Armenia Quindío Colombia. Correo electrónico: carloschacon@uniquindio.edu.co

Recibido: Septiembre 1 de 2011

Aceptado: Diciembre 13 de 2011

\section{RESUMEN}

El presente escrito, es emergencia de investigación doctoral en educación, y muestra el trayecto investigativo, de carácter cualitativo, de corte filosófico, epistémico, estético-bio-poético y educativo ambiental, el cual se construye desde un método particular de indagación, a través de lograr la inmersión en instituciones educativas y su itinerancia por ellas, para encontrar anuncios, indicios, rasgos del pensamiento ambiental del maestro, como viáticos, los cuales, se conjugan, se hacen vecinos, en una meseta de pensamiento llamada tendencias de pensamiento ambiental, que en clave filosófica ambiental, se constituye en hallazgo crucial de la tesis. Tesis que además tributa a la transformación del pensamiento ambiental del maestro, a través de una meseta de pensamiento en las claves de modos del habitar la tierra y el pensamiento del mundo de la vida, enunciada como Ethos-Cuerpo en clave de Bio-Geo-Poéticas del Habitar. Finalmente, muestra emergencias investigativas, que anuncian potencias del pensamiento ambiental del maestro, y promueven la incorporación de la filosofía ambiental en su pensamiento ambiental, y de manera decisiva, para la transformación de la educación ambiental.

Palabras clave: filosofía ambiental, mundo de la vida, maneras del habitar la tierra, pensamiento ambiental del maestro, mesetas de pensamiento.

\begin{abstract}
This writing emerges as part of a doctoral research in Education. It shows a qualitative investigation comprehended as a philosophical, epistemic aesthetic, bio-poetic and environmentally educational style, built on a particular inquiry method, by being immersed in educational institutions so as to find evidence, signs and features of the teachers' environmental thinking. These aspects are combined, and put together in a plateau of thought known as trends in environmental thinking, which in turn, become a crucial finding in the thesis, in environmentally philosophical terms. This thesis contributes to the transformation of the teacher's environmental thinking, through a plateau of thinking in key modes of inhabiting the earth, and the thinking of the world of life, stated as ethos-body in a sense of bio-geo-poetics inhabiting. Finally, this research shows investigative effects that announce the empowerment of the teacher's environmental thinking, and promote a decisive incorporation of an environmental philosophy in his/her environmental thinking so as to transform environmental education.
\end{abstract}

Key words: Environmental philosophy, world of life, ways of inhabiting the earth, teacher's environmental thinking, plateau of thought.

\section{INTRODUCCIÓN}

Los propósitos investigativos se cumplen en la manera del hallazgo de tendencias del pensamiento ambiental del maestro, y la formación de un Ethos-Cuerpo en clave de Bio-Geo-Poéticas del Habitar, los cuales se nutren de significados desde el Ethos como "el sentido de-habitar-o-morar-" (González, 1996, pp. 10-11), en maneras posibles del cuerpo simbólico, como engarce, entre su humanidad sensible y el sentir terrestre, como 
cuerpo como lugar del acontecimiento, cuerpo simbólico en espaciamiento con sentidos de la tierra. Así mismo, en claves de Bio-Geo-Poéticas del Habitar, en el sentir la tierra en el habitar, pues "el habitarhumano es preciso pensarlo como un habitar-poético" (Pineda, 2009, p. 31). Por estos motivos, desea la disposición dialógica con el lector, en las claves de la organización particular, la filosofía, la episteme, la estética, la poética, la educación ambiental y la vida, y en las formas de pensar las maneras de habitar la tierra, y la interpretación profunda del mundo de la vida, todas ellas como potencias de la filosofía y el pensamiento ambiental.

\section{Plexo de problematización:}

Es una investigación que indaga rasgos, nociones, indicios, señales del pensamiento ambiental del maestro, justamente porque no ha sido preguntado, y porque es imposible predecirlo debido a su condición única del pensar. Derivada de esta condición, la manera cómo piensa ambientalmente el maestro y la filosofía ambiental, en claves de los modos interpretativos del habitar la tierra y el pensamiento profundo del mundo de la vida, no han sido tenidos en cuenta al momento de formular los propósitos educativos ambientales, y tampoco la relación existente entre el pensamiento ambiental del maestro y la educación ambiental, toda vez el maestro piensa ambientalmente de diferentes formas, las cuales se traducen en sus maneras de orientar la educación ambiental; y la educación ambiental, que tiene como objetivo la formación del estudiante en temas ambientales desde los modos de la educación, impartidos por el maestro a través de la educación ambiental institucional; pero ambos, construidos desde múltiples miradas, que dan cuenta de las formas como se perciben la naturaleza, la sociedad, la cultura y los demás acontecimientos ligados a la tierra, que si bien está ligada al concepto de ambiente, es signada por una separación clásica de percibir el mundo, lo que recuerda la escisión y la dualidad características del pensamiento cartesiano, el cual significa, aproximarse a los principios de la modernidad, en la que predomina la escisión naturaleza-cultura; lo que se evidencia, en cuanto es "muy significativo que el currículo de nuestras escuelas esté, cien años después de la emergencia de las teorías de la incertidumbre, la de sistemas, y la ciencia de la ecología, presentándole al estudiante una naturaleza reducida a -objetomedible y escindida en dos categorías aún hoy irreconciliables: naturaleza-sociedad" (Noguera, 2007, pp. 20-21). Se reitera así, que el maestro no es ajeno a la constitución de un sujeto de la modernidad, e inmerso en un panorama de educación ambiental intencionada en la preservación de los recursos naturales, y de manera expresa, la contribución al desarrollo, en donde se observa, que ninguno de los objetivos contenidos en el diseño de la Política Nacional de Educación Ambiental en Colombia del año 2002 , se ocupa de incorporar pensamiento ambiental del maestro, ni de promover su formación filosófica ambiental; lo que se hace evidente, además, en las Conferencias Internacionales, y decretos con relación a la educación ambiental. En el mismo sentido, porque la pretensión es "formar maestros (...), para la resolución de problemas ambientales" (Torres, 1996, p. 89). De manera similar, en los Lineamientos CurricularesCiencias Naturales y Educación Ambiental, cuyos objetivos de la enseñanza de las ciencias naturales y educación ambiental, son exclusivos para el estudiante, para que "desarrolle un pensamiento científico que le permita contar con una teoría integral del mundo natural dentro del contexto de un proceso de desarrollo humano integral, equitativo y sostenible" (Figueredo E, Escobedo H, 1998, p. 110).

\section{Construcción del modo propio investigativo: trabajo de campo como geo-grafía empírica.}

Es una manera investigativa en donde "el método es un discurso, un ensayo prolongado de un camino que se piensa. Es un viaje, es un desafío, una travesía, una estrategia que se ensaya para llegar a un final pensado, imaginado y al mismo tiempo insólito, imprevisto y errante. No es el transcurrir de un pensamiento seguro de sí mismo, es una búsqueda que se inventa y se reconstruye continuamente" (Morín, Ciurana y Motta, 2002 , p. 17). De esta manera, la investigación recurre a la construcción de un modo particular investigativo, desde el interés crucial, en cuanto consulta-ausculta el pensamiento ambiental del maestro, para lograr los propósitos investigativos de encontrar el pensamiento ambiental del maestro, como tendencias de su pensamiento ambiental, y como manera para la formación del Ethos-Cuerpo del maestro en clave de Bio-Geo-Poéticas del Habitar, a partir de hacer alianzas entre su pensamiento ambiental y la filosofía ambiental, que permitan que su pensamiento ambiental se transforme. En este sentido, pide novenir-de-otra, sino hacer-se-otra investigación, en llamamientos desde los indicios del maestro, que se 
modulan y emergen para un conocimiento tratado, abierto, puesto en crisis

En este sentido, es un método, que no desea ser un conjunto de recetas, de fórmulas eficaces para la realización de un resultado previsto que presupone deducciones desde su inicio, pues implica indagar el pensamiento ambiental del maestro, y por tanto, no pretende catalogar, estratificar, clasificar, ni obtener resultados que se dispongan en cuantificación, en datajes apilados, ni en esquemas estadísticos. Además, requiere en la convocatoria al maestro, acoger su palabra escrita en el mayor respeto $y$ cuidado, puesto que de esta manera afectuosa y considerada, se logra que el maestro cuente-narre su pensamiento, que está ligado a sus condiciones de intimidad, porque "la intimidad está ligada al arte de contar la vida” (Pardo, 2004, p. 29). Así, es una labor investigativa, que contiene un método que activa formas interpretativas y deja a discreción del investigador cierta libertad, debido a que "puede elegir y poner el acento donde le plazca, (...) en todo caso, (...) hallable en el texto" (Auerbach, 1950, p. 524).

Se recurre a la construcción del método particular de indagación, que significa y cobra valor investigativo en la manera del trabajo de campo como geo-grafía empírica, el cual se adelanta en términos de dos preceptos fundamentales: Ia Inmersión y la Itinerancia. Es decir, que para encontrar el pensamiento ambiental del maestro, se parte de dos modos particulares: el primero de ellos la Inmersión en el lugar latente: La Institución Educativa, y que se entiende, como la llegada al lugar de labor del maestro, la que se logra por tener grados de afinidad académica, personal y profesional en educación ambiental, por cierta complicidad afectiva por el trabajo educativo ambiental del maestro, y por pertenecer a una institución educativa formadora de maestros, como es el caso de la licenciatura en Biología y Educación Ambiental de la Universidad del Quindío. Esto es esencial, puesto que se precisa cierto grado de igualdad, de simpatía, de propensión laboral y de pensamiento para hacer posible ser recibido en la Institución Educativa.

En este momento de la fase empírica, la Inmersión en las Instituciones Educativas del Departamento del Quindío, se logra mediante el ofrecimiento de una conferencia en torno a la educación ambiental para todos los docentes y directivos docentes. Esta conferencia, contiene diversos nodos conceptuales y de filosofía ambiental, para hacer locus en el pensamiento ambiental del maestro, y en el interés de alentarlos para que se dispongan a hacer alianzas entre su pensamiento ambiental y la filosofía ambiental, que orienten su reforma de pensamiento.

De esta manera, se logra la llegada a (9) nueve Instituciones Educativas del Departamento del Quindío, y así comienza el segundo modo del trabajo en el campo, llamado Método del Espacio Itinerante, que conceptualmente se considera como "una dinámica, que consiste en recorrer el espacio tomando conciencia de él (...). Libera la imagen del mundo sobre un itinerario" (Leroi-Gourhan, 1971, p. 315), lo que significa, que el método del espacio itinerante, es recorrer en la manera de la itinerancia las Instituciones Educativas, las cuales se convierten en los lugares de itinerancia.

Ahora bien, en estas Instituciones Educativas-Espacios de Itinerancia, se obtienen (301) trescientos un escritos, como huella testimonial, como pintura escrita del pensar, y elaborados en torno a resolver el interrogante de: ¿cuáles son los rasgos del pensamiento ambiental del maestro?; y para el efecto, les plantea la pregunta: ¿qué significa para usted pensamiento ambiental? De esta manera, se consigue que el maestro a través de sus escritos, muestre por su contenido, por lo que anuncian, por lo que auguran, por lo que insinúan, su pensamiento ambiental, lo que significa en hallazgo, el encuentro con su singular manera de pensar ambiental. Estos escritos, una vez obtenidos, se consideran como viáticos, como provisión, como viaje, como el camino para hallar el pensamiento ambiental del maestro, desde los cuales se procede a la obtención de la meseta de pensamiento llamada tendencias del pensamiento ambiental del maestro. De este camino de investigación, también se desprende la apuesta de escribir en tonalidad filosófica, estética, poética una meseta llamada EthosCuerpo en clave de Bio-Geo-Poéticas del Habitar, como tributo al pensamiento ambiental del maestro, en la manera del complemento, de la amplificación, para acompañarlo en la transformación de su pensamiento ambiental. Mesetas que se enuncian a continuación:

Meseta primera: tendencias del pensamiento ambiental del maestro.

Las mesetas se entienden como regiones extensibles 
del pensamiento ambiental del maestro, las cuales se logran y enuncian, mediante un proceso de organización conceptual de los escritos, en la manera de la conexión epistémica y filosófica entre ellos, al tener en cuenta lo que dicen, a lo que tienden, por sus afinidades, similitudes y vecindades de pensamiento. Es "emplear metódicamente la imagen de un despliegue territorial, que ya ha empezado a aparecer con los términos de vecindad y contigüidad. Poesía y filosofía ocupan territorios colindantes" (Nicol, 1990, p.
99). Es una vecindad que no se trata de un espacio territorial, como dimensión, sino como significados ordinales de la expresión de vecindad simbólica de la palabra y de pensamiento. Consideración de vecindad, que permite construir 9 (nueve) tendencias, figura 1 , cuyos enunciados, configuran una manera de nombrarlas con relación a claves de la filosofía ambiental, no teleológicas, ni finalistas y que comportan el hallazgo del pensamiento ambiental del maestro, punto crucial del plexo de problematización.

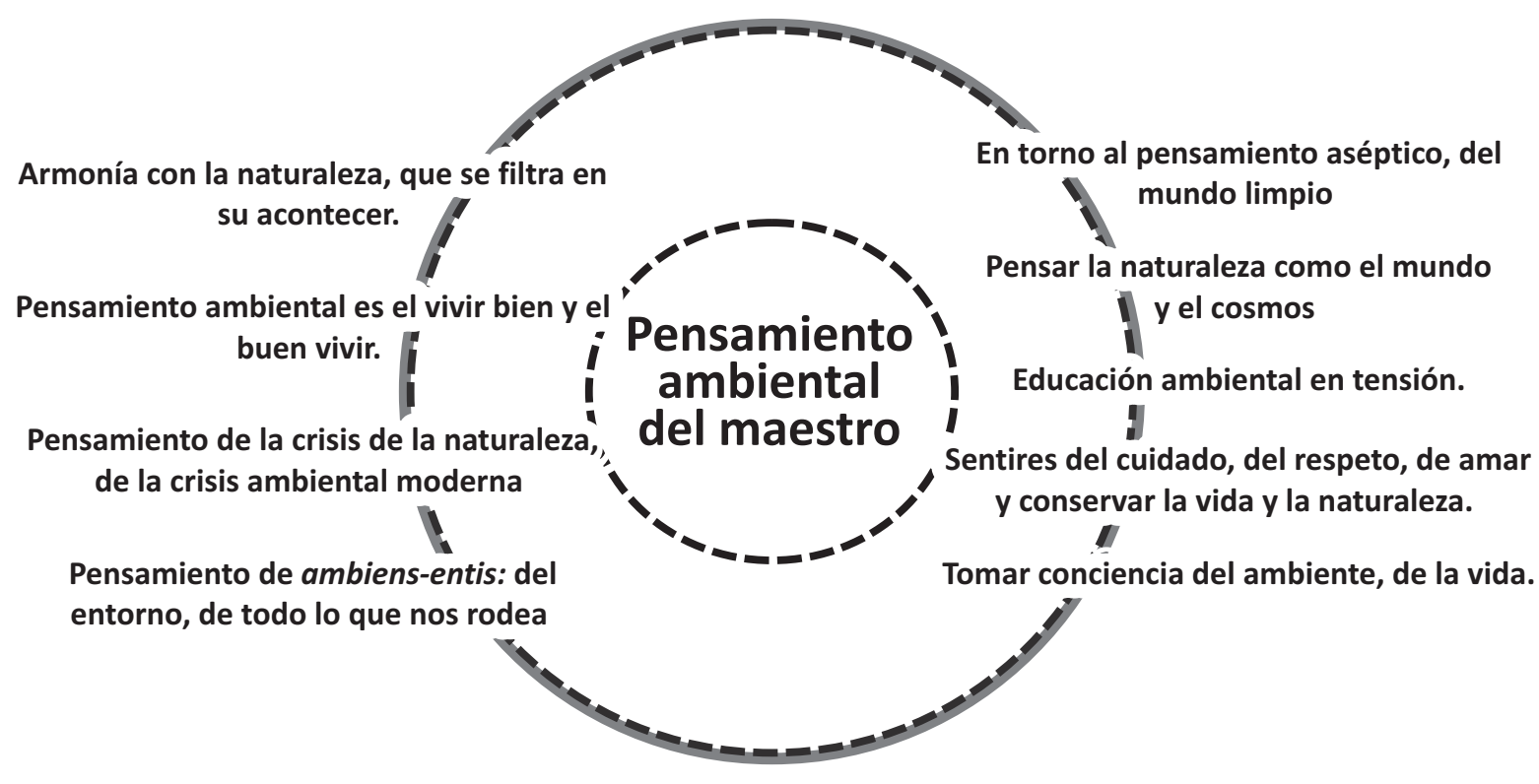

Figura 1: Tendencias del pensamiento ambiental del maestro.

Así, son tendencias que a su vez, dan cuenta del hallazgo del pensamiento ambiental del maestro, y que se amplifican en claves de la filosofía ambiental, para darle valor y sedimento a su pensamiento ambiental, de la siguiente manera: Armonía con la naturaleza, que se filtra en su acontecer; es armonía que emerge como estabilidad temporal, en el modo de figuras extensibles de lo bello que nacen producto de las relaciones armónicas, tal como se dice desde Heráclito: "la armonía del mundo descansa en una tensión de contrarios, como la armonía de la lira" (Apel, 1961, p. 27). Pensamiento de ambiens-entis: del entorno, de todo lo que nos rodea; pensamiento de todo lo que nos rodea, en posibilidad espacio-naturaleza que comporta las finuras, trenzas, filigranas del tejido virtuoso de la vida, que no acoge sólo los despojos, los restos, los residuos de las formas inertes, las formas cosificadas heredadas por las miradas tecno-clásicas del mundo, los prismáticos mediadores para alejar los contenidos de la vida, sino, que contiene como lugar, el devenir de la vida, el mundo de la vida. Medio que rodea, que merodea, que merodea, en la manera de la mezcla del cuerpo y el medio, "a mí no me gusta llamar medio al lugar donde mi cuerpo habita, prefiero decir que las cosas se mezclan entre sí y que yo no soy la excepción, me mezclo con el mundo que se mezcla en mí" (Serres, 2003, p. 102). Pensamiento ambiental es el vivir bien y el buen vivir; es un pensamiento Abyayalense: el vivir bien y el buen vivir; en AbyaYala, como resignificación de América, y que contiene como partitura los significados de tierra madura, tierra viva, tierra prodigiosa, tierra en florecimiento, tierra en plena madurez, como una especie de contrapartida, de resistencia a los códigos de intervención segregador, esclavizante. Construcción de pensamiento multicultural, que no puede banalizarse en los sentidos 
modernos de una manera de vivir bien basado en la mera consecución de bienes materiales, ni una vindicación indigenista de los saberes tradicionales; se trata, de "estar bien para vivir bien (...), es una propuesta de la cultura de la vida de todos los pueblos indígena originarios" (Huanacuni, 2010, p. 84). Pensar la naturaleza como el mundo y el cosmos; es pensar la naturaleza universal en sentido global, cósmico; así, es la naturaleza como physis, naturaleza en su forma amplia, que es semejante al mundo natural, al universo físico. Naturaleza que contiene la generalidad de los seres vivos, su asociación con objetos inertes o inanimados, en sus maneras diversas y cambiantes. También pensamiento de la naturaleza, en la manera como "la humanidad ha terminado por dominar a la naturaleza, (...) ha abusado de ella y la ha maltratado, y ahora debe vivir con las consecuencias ambientales y sociales de su acto prometeico" (Arnold, 2000, p. 1617). Naturaleza como la describió Alexander von Humboldt, "un gran todo animado por la respiración de la vida" (Arnold, 2000, p. 57). Tomar conciencia del ambiente, de la vida, es darse cuenta como percatarse, como notar, como advertir, el mundo que se habita. Es una expresión del sentir, de las actitudes deseantes, no substraída a las sensaciones en piel, pues "la piel interviene entre numerosas cosas del mundo y las mezcla" (Serres, 2003, p. 102). Extensiones sensoriales, mundo de la percepción, posibilidades del recuerdo, del repaso, de la remembranza, del mundo invocado, traído a los lugares del pensar, del imaginar, del anticipar sucesos del mundo. Darse cuenta como ponerse en contacto con uno mismo, y darse cuenta de lo que se siente; porque "(darse cuenta de la vida, de tenerla en cuenta) no es más que el arte de vivir. Vivir con arte es vivir contando la vida, cantándola, paladeando sus gustos y sin sabores" (Pardo, 2004, p. 30). Sentires del cuidado, del respeto, de amar y conservar la vida y la naturaleza; expresión del cuidar, que encuentra en el pensamiento ambiental, lugar de implicación, de interpretación posible y de despliegue en las significaciones del cuidado, del amor. Formas del cuidar por el respeto, en donde no se trata de añadir a los sistemas naturales unas formas fácticas ni técnicas para su recuperación, para que logren su estado de homeostasia, su estado de bienestar. Se trata, de "adoptar una actitud moral básica hacia la naturaleza, que llamo, respeto a la naturaleza" (Taylor, 2005, p. 9). Manera de la valoración de la naturaleza que no es motivo de análisis, de experimentaciones y de confirmación empírica, tampoco de la consideración eminentemente biológica de la constitución de los ecosistemas. Es una valoración en la medida del respeto que "reconoce el valor intrínseco de todos los seres vivos y ve a los humanos como una mera hebra de la trama de la vida" (Capra, 1998, p. 29). En torno al pensamiento aséptico, del mundo limpio; como pensamiento de un mundo limpio en donde la basura dispersa por doquier en las superficies del mundo, significan la expresión de la suciedad que se debe abolir para tener una naturaleza que tiene como destino la perfecta armonía. Estado limpio que se originó del griego lympha, de significado agua, el agua que todo lo limpia, que arrastra la suciedad, que purifica, que desintoxica, como linfa que recorre el mundo limpiándolo de los residuos infecciosos. Mundo sin basura, del latín versura, derivado de verrere que significa barrer; este barrer que entraña la retirada de los productos que generan incomodidad, lo que hay que barrer como acción, como técnica, como actitud, como mantener las condiciones de inicio de una naturaleza limpia. Pensamiento de la crisis de la naturaleza, de la crisis ambiental moderna; crisis con origen en la modernidad, que refleja una cultura actual globalizante anclada en las lógicas tecnocráticas y la cientificidad, que trae como consecuencia, entre otras, el desdén por la cultura y la naturaleza. Pues, "el cimiento del desarrollo sin límites de la ciencia y la tecnología fue la profunda escisión entre cultura y naturaleza que, bajo las figuras de cielo y tierra o alma y cuerpo, llegó a la modernidad para convertirse en sujeto y objeto" (Noguera, 2004, pp. 28-30). Educación ambiental en tensión; es pensamiento de una educación ambiental instrumentalizada que arrastra consigo al maestro, quien tiene que afrontar un cúmulo de problemas, e intercambiar su actitud formadora, por la explicación de los fenómenos que causan impactos ambientales, en "la ambición de un saber absoluto" (Leff, 2006, p. 53). Esto hace pensar que el maestro aún contiene el lastre civilizatorio y academicista del sujeto de conocimiento, que no es otro que el sujeto de la ciencia moderna.

Meseta segunda: Ethos-Cuerpo, en clave de Bio-GeoPoéticas del Habitar.

Esta escritura en inacabamiento, es un tributo al pensamiento ambiental del maestro, y como esperanzada semblanza, para la transformación de su pensamiento ambiental. Se inscribe en el cómo amplificar desde la filosofía ambiental, su 
pensamiento ambiental, para transformarlo. De esta manera, los siguientes (7) siete enunciados (figura 2), que orbitan el propósito de formación del maestro como Ethos-Cuerpo en clave de Bio-Geo-Poéticas del
Habitar, se expresan para aportar al nodo problematizador, de la ausencia de filosofía ambiental en el pensamiento ambiental del maestro:

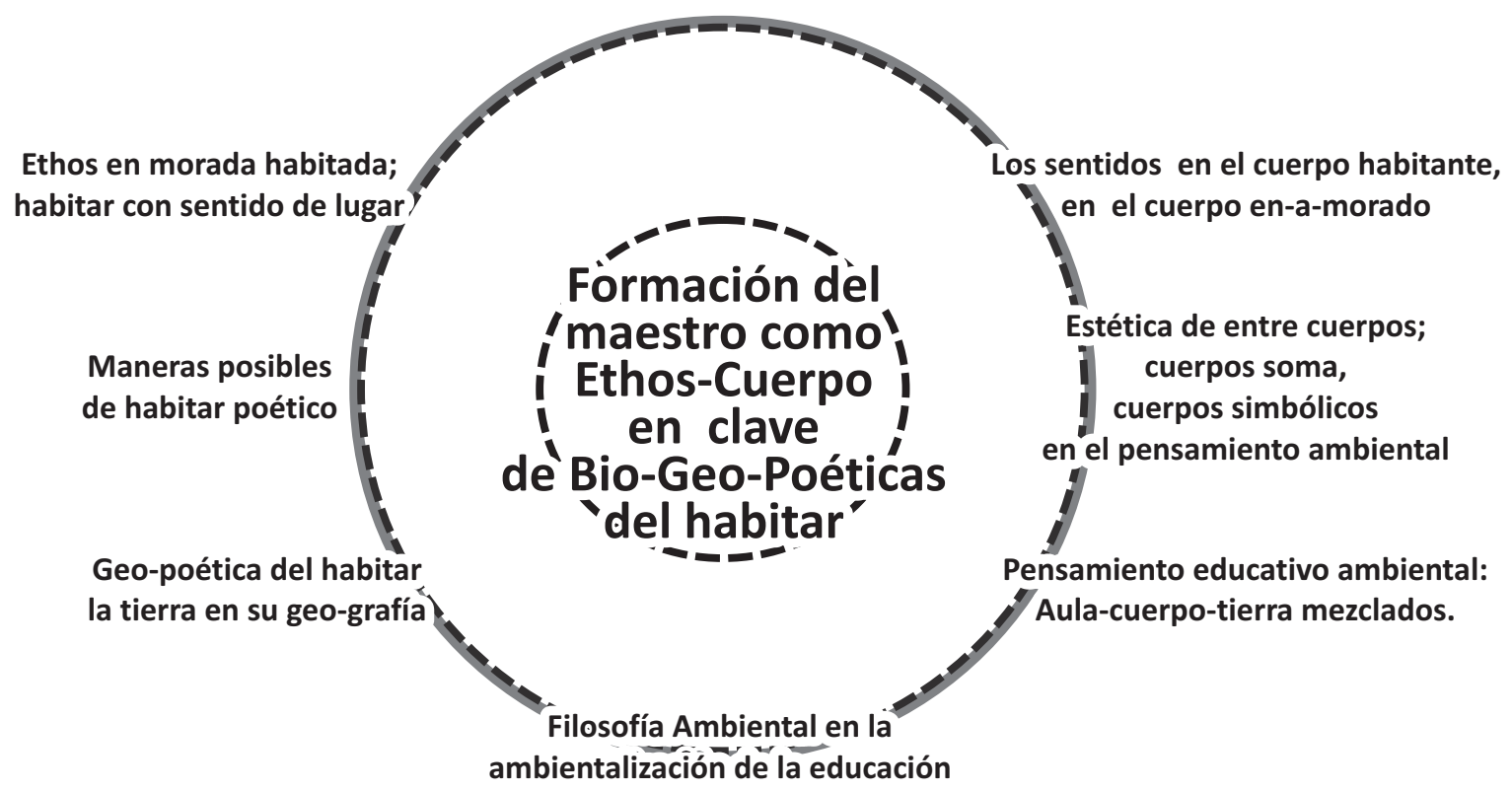

Figura 2: Enunciados que orbitan-convocan filosofía ambiental para la formación filosófica ambiental del maestro como EthosCuerpo en clave de Bio-Geo-Poéticas del Habitar

Ethos en morada habitada; habitar con sentido de lugar; como Ethos en sentido del habitar, y de rasgo etológico del espacio y el tiempo, en el que el hombre habita, como variedad de formas de habitar la tierra plenamente, en consideración de ser el único lugar cósmico como morada. Anuncios del Ethos, como "el sentido de -habitar- o -morar- (...), entrañado en el ethos humano-: remite a la idea esencial de-morada interior-. El Ethos es -lugar- humano de seguridad existencial” (González, 1996, p. 10). Habitar con sentido de lugar, pues " habitar en cuanto tal supone ya una implícita teoría del lugar, ligada inexorablemente, a lo que como seres humanos somos en nuestra dimensión, tanto espacial (la cual compartimos con los demás seres de la naturaleza) como espaciante; esto es, cargada de sentido y significación"(Yory, 2007, p. 373). Maneras del habitar, como apego a la tierra, a los procesos de la naturaleza, en la manera del cuerpo que fluye entre la naturaleza de aspecto casa, de aspecto territorio, de aspecto terruño. Pensamiento del habitar la tierra en sus tensiones, en sus dramas, en sus apremios, pues "el problema ambiental surge de los posibles conflictos entre ecosistema y cultura" (Ángel, 1996, p.46). El Habitar la casa, la choza, la cuenca o la guarida, en imaginación desatada para construir el lugar soñado; el sentido de la casa. Casa inconmensurable con el afuera conectado, "porque la casa es nuestro rincón del mundo (...), nuestro primer universo. Es realmente un cosmos" (Bachelard, 2000, p. 34). Maneras posibles de habitar poético; como habitar poético en el espacio consentido, en el espacio abrazado por las pasiones suscitadas por el encuentro pleno o clandestino de sus moradores; pues "el habitar poético requiere de un modo distinto de escuchar y prestar atención a otras formas de morar, otras vecindades y otras prácticas. Algo fugaz que siendo profundo registra siempre lo más vivo" (Pineda, 2004, p. 1-5). Los sentidos en el cuerpo habitante, en el cuerpo en-a-morado, doble revés del habitante-habitado, en el cuerpo enamorado que mora la morada, cuerpo en sensibilidad expandida. Pensar con sentidos de la tierra, de la vida; en donde interesarse por las vivencias, por las maneras del morar la tierra, por la experiencia sensible y la percepción estética. Estética de entre cuerpos; cuerpos soma, cuerpos simbólicos en el pensamiento ambiental; 
como cuerpos de la modernidad que se construyen en la medida del autor, en el uso de los medios de divulgación, que reafirman la condición individualista propuesta por el campo social. Estética de los cuerpos que desde una "estética de lo americano (...), es una forma herética de encontrar dentro de lo bárbaro (el supuesto mal) a la civilización (...), correlación humano natural, que se opone al refugio occidental en el signo (y en el sujeto)" (Grosso, 2009, pp. 1-3). Cuerpo al tenor del aparato estatal de la educación física, de la justa deportiva o simplemente como el parecerse a otro como imagen especular; en una especie de "liberación del cuerpo (...), que olvida (...), que el hombre es indiscernible del cuerpo que le otorga espesor y sensibilidad de su ser en el mundo" (Le Breton, 2008, p. 9-10). Geo-poética del habitar la tierra en su geo-grafía; en ocasión de tiempo-lugar de manifiesto natural, para acudir al acto de alianza de espacialidad terrestre con el pensamiento ambiental, en esperanza de juntura poiésica; es decir en poiesis, palabra griega que indica relación del hombre con la naturaleza en las maneras de la creación, en tanto habitabilidad creativa. Es así, que pensar poiésicamente es una emergencia, es una transformación del pensamiento, de construcción estética frente a la vida. Es creación como en el artesano, en el poeta, por eso "la palabra poiesis es preclara metáfora de creación" (Zapata, 2006, pp. 137168). Pensar en situado vital, y en viaje posible de geopoética como tierra en sus geo-grafías, es manera profundamente ambiental de pensar la tierra en que vivimos; pues, "la geo-grafía es escritura de la tierra (...), significa que la tierra misma, ella, escribe y describe deslenguada su lengua; su lenguaje es el paisaje; sus letras los muebles e inmuebles que decoran y constituyen el espacio" (Pardo, 1991, p. 61). Odiseas del cuerpo en la tierra inscritas en las geo-grafías terrestres, en una ontogénesis, en la manera de su evolución trashumante entre -lugares. Pensamiento educativo ambiental: Aula-cuerpo-tierra mezclados, como promenade por la vida; promenade, palabra francesa que significa paseo, como acto de pasear, de pasearse por la vida en el acto educativo de cualidad filosófica-estética-poética ambiental. Es el devenir educativo ambiental, como forma de educación sobre la vida, que acoge multiplicidad de saberes, y en salida airosa al discurso que hace rúbrica a lo imperecedero de la acera del frente, más de lo mismo. Aula en donde suceda el cierre del bostezo academicista de corte enciclopedia, hacia el oscilum de una ambientalización de la educación como poetización. Pensamiento educativo ambiental en una especie de ritornelo que conecte las experiencias, los saberes, las expresiones de la tierra y la cultura. Que se ocupe interesadamente del contexto, que exige "el pleno empleo de la sensibilidad, de la perceptualidad, de la razonabilidad, de la paisajística, del ensayo, del pensamiento de la subjetividad despierta" (Contreras, 2007, p. 253). Pensamiento educativo ambiental en complejidad creciente, para disolver las aduanas del conocimiento, las parcelas conceptuales, y en la superación, de las "rutinas mentales que automatizan la vida y anulan el pensamiento" (Martínez, 1997, p.49). Filosofía ambiental en la ambientalización de la educación; en este sentido, abrirse al mundo, en ejercicio inalienable de ejercer la cualidad de la fascinación, de la sensibilidad, de la pasión, de permitir la curiosidad, y, así, superar la dureza del conocimiento tecnocientífico. Saberes de orden biológico u otros disciplinares y pensamiento ambiental, que entienden, que el dejo de la sola respiración fisiológica, no es suficiente para vivir, vivenciar, pervivir en el mundo y, que requiere además, sensibilidad estética, erótica, poética y simbólica en forma de junturas creadoras; en "brisure/juntura. (...) Articulación por medio de una bisagra de dos partes de una obra de carpintería. (...) La juntura de un postigo, (...) origen de la experiencia del espacio y del tiempo" (Derrida 1978, p.81-82). Es así, que la educación ambiental se ambientaliza, a través de recomponerla con lecturas ampliadas, complejizantes e hipertextuales del mundo de la vida. En aliento poético de la ambientalización de la educación, que requiere y llama "un reencantamiento de paideia, una estetización del aula, un diálogo de saberes y sabores, un reconocimiento del otro en su alteridad, una salida del centro, una pérdida del centro y una ganancia de lo marginal, lo periférico, lo despreciado por la razón instrumental: una poetización de la vida" (Noguera, 2010, p. 31).

\section{Emergencias de la investigación.}

Emergencias de la investigación que muestran un estilo de conclusiones del trabajo investigativo, y que revelan la manera como la investigación ha atendido al interrogante crucial, que pregunta, por ¿cuáles son los rasgos del pensamiento ambiental del maestro?, y los propósitos fundantes en cuanto encontrar los rasgos del pensamiento ambiental del maestro, y su formación 
como Ethos-cuerpo en clave de Bio-Geo-Poéticas del Habitar. En este sentido, las siguientes emergencias, denominadas así, por su propiedad holista, por ser salidas de las inter-dependencias, de las tramas del pensar filosófico ambiental ocurrido en el ejercicio de la tesis, como manera de dar cuenta de los hallazgos de la gesta investigativa. Reconocen lo que ha acaecido en el pensamiento ambiental del maestro, a través del encuentro en las maneras de la inmersión y la itinerancia por las Instituciones educativas, y las maneras como esta investigación muestra caminos desde la filosofía ambiental para coadyuvar a la transformación de su pensamiento ambiental:

Investigación que devela rasgos de Pensamiento ambiental bio-poético-estético, pues los maestros remarcan la potencialidad de su pensamiento ambiental, en una bio-estética-poética, que se puede leer desde sus construcciones lingüísticas-escriturales, como modos de aprehender el mundo de la vida, las que son anunciadas en la necesidad de la armonía con la naturaleza como plástica del logos, que llama a la traducción de los lenguajes científicos, pues permanentemente anuncia el sentido de la belleza, de la armonía de la vida y la naturaleza. Maestro que muestra pensamiento de la vida, de la naturaleza, en la preocupación por la crisis ambiental y por los problemas ambientales asociados a pensar la naturaleza, la vida como recurso. Preocupación que se traduce en atender a los sucinto de la norma, del mandato, de la utilización de la educación ambiental como herramienta. Reclamo de una educación comprometida con la vida, pues el maestro la siente alejada de las complejidades del mundo de la vida, y porque el trabajo educativo ambiental en la escuela sea móvil al tenor de pensarla como labor de arte, de hacer de la escuela el territorio de la corporeidad, de la escuela habitada. Maestro que está en una común-unión con la escuela y con la vida, que se suscita temporal y permanente en las maneras de pensar no totalitario, que no desea el desgate del activismo inocuo, sino de la actividad del pensar, que haga de sus prácticas labor de sentido para la transformación propia, y en la búsqueda de intersticios para mover lo incólume de las instituciones rígidas y sus edificios conceptuales. Maestro que plantea la urgencia de una reforma del pensamiento, causada por el agotamiento, el cansancio debido a la erudición enciclopédica para pensar la vida y por las cargas impuestas por la educación ambiental institucionalizada, y así, cambiar la costumbre de pensar la vida fraccionada, por partes, y del pensamiento del ambiente escindido de la naturaleza y la cultura. Distancia de sentido entre educación y pensamiento ambiental, puesto que la educación ambiental, tal y como la conoce el maestro, y él, su pensamiento filosófico ambiental, no tienen confluencia potente, pues no contiene la alteración necesaria para la ignición de pensar el mundo de la vida y de las formas de habitar la tierra de otras maneras; y mucho menos, la inmanencia necesaria para que orbiten las estelas desu pensamiento ambiental, el cual, a su vez, está en franco alejamiento de los agenciamientos educativos, de la acomodación laboral para atender las urgencias de la educación ambiental, pues esas no son sus maneras de pensar ambientalmente. Imperiosa necesidad de la transformación de la educación ambiental desde el pensamiento filosófico ambiental del maestro y la filosofía ambiental, en salida a universos finitos de la gestión o lo valoral axiológico, que permita, que sus huellas, sus pinturas de vida, su sentir ambiental, su filosofía ambiental, sus percepciones, sus emociones en sentido del lugar, aligeren la plomada de la educación ambiental instituida. Hallazgo del pensamiento ambiental del maestro, en la manera de tendencias de pensamiento, como maneras de rotar, de virar, de acercarse, de hacerse vecino al pensamiento ambiental del maestro, como amplificación de su palabra emergida, que hace alianzas con la complejidad creciente del mundo de la vida, con los modos de habitar la tierra, con las significaciones de la educación ambiental puesta en crisis, y otros que han motivado tal esfuerzo afectivo del pensar. Son tendencias de pensamiento ambiental, construidas y revestidas de las potencias de fuente maestro, las cuales son puestas en resonancias amplificación, reenvío en claves del pensamiento ambiental. Investigación, que se prueba en su acontecer y aporta retos de modificación del pensar, en clave de Bio-Geo-Poéticas del Habitar, para la formación de un-otro Ethos-Cuerpo del maestro, como oscilación del pensar la vida y las maneras del habitar la tierra, claves potentes del pensamiento ambiental. Tesis que aporta a la re-construcción de una educación ambiental, desde la filosofía ambiental, ya incorporada en el pensamiento ambiental del maestro, el cual podrá convocarla en sus diseños, en sus soportes conceptuales y filosóficos, para no seguir en el riesgo de una educación anclada al pensamiento de facto únicamente, sino convocante de la filosofía ambiental, 
ya contenida en el pensamiento del maestro. Se siente la necesidad, y se espera el compromiso que el pensamiento ambiental del maestro y la filosofía ambiental, se incorporen de manera decidida en la educación ambiental formalizada, para movilizar los estándares y competencias referidos a la educación ambiental, el rediseño de las prácticas educativas y los diseños curriculares. Además, incorporar pensamiento ambiental del maestro y la filosofía ambiental a los proyectos ambientales escolares (PRAE), en los proyectos ciudadanos de educación ambiental (PROCEDA), en los comités municipales de educación ambiental (COMEDA), en los comités interinstitucionales departamentales de educación ambiental (CIDEA), en las corporaciones autónomas regionales (CAR), en las ONGs ambientalistas, y otros que tengan que ver con el campo de la educación ambiental.

Desde estas consideraciones, se espera que el maestro se disponga en actitud deseante, arrojada y afectiva, a estas vías posibles, a estos trayectos de pensamiento ambiental, como inscripciones, tanto en la gesta personal como la actitud institucional, y no en la jurídica del deber ser como imperativo moral, sino en las maneras del pensar en condición potente de cuerpo simbólico, en maneras diferentes de interpretar el mundo de la vida y las formas del habitar la tierra.

\section{BIBLIOGRAFÍA}

Ángel, A. (1996). El Reto De La Vida: Ecosistema y Cultura. Una Introducción al Estudio del Medio Ambiente: Ecofondo. Bogotá.

Apel, M. (1961). Diccionario de filosofía: Unión Tipográfica Editorial Hispano Americana.

Arnold, D. (2000). La naturaleza como problema histórico. El medio, la cultura y la expansión de Europa: Fondo de Cultura Económica. México.

Auerbach, E. (1950). Mímesis: Fondo de Cultura Económica. México.

Bachelard, G. (2000). La Poética del Espacio: Fondo de Cultura Económica. México.

Capra, F. (1998). La trama de la vida. Una nueva perspectiva de los sistemas vivos: Anagrama. Barcelona.

Contreras, L. (2007). Subjetividad en despertar perceptual. El contexto como campo de aprehensión y de experimentación. En:Zemelman Hugo. El ángel de la historia: determinación y autonomía de la condición humana: Anthropos.Barcelona

Derrida, J. (1978). De la gramatología: Siglo XXI Editores. México.

Figueredo E, Escobedo H. (1998). Lineamientos Curriculares Ciencias Naturales y Educación Ambiental. Áreas obligatorias y fundamentales. Ministerio de Educación Nacional: Cooperativa Editorial Magisterio. Colombia.

González, J. (1996). El Ethos, destino del hombre: Fondo de Cultura Económica. UNAM. México.

Grosso J.L. (2009). De lo luminoso a lo tenebroso. Educación, matrices epistémico-prácticas populares interculturales y ciudadanía. Primer encuentro internacional de proyectos de investigación "ética, derechos humanos, educación y ciudadanía" Proyecto de Investigación "Ética y Ciudadanía desde el enfoque filosófico intercultural" Biblioteca Nacional, Buenos Aires. Recuperado de http://encuentroproyectos.com.ar/R-JLGrosso.

Huanacuni F. (2010) Para vivir bien hay que estar bien. En: Construcción de la Sustentabilidad desde la Visión de los Pueblos Indígenas de Latinoamérica". La Paz - Bolivia. Recuperado de http://www.reflectiongroup.org/stuff/vivirbien.

Le Breton, D. (2008). Antropología del cuerpo y modernidad: Nueva visión. Buenos Aires. 
Leff, E. (2006). Aventuras de la epistemología ambiental: de la articulación de las ciencias al diálogo de saberes: Siglo XXI Editores. México.

Leroi-Gourhan, A. (1971). El gesto y la palabra: Ediciones de la biblioteca-Universidad Central de Venezuela. Venezuela.

Martínez, M. (1997). El paradigma emergente. Hacia una nueva teoría de la racionalidad científica: Trillas. México.

Morín E, Ciurana E, Motta R. (2002). Educar en la era planetaria: Gedisa. Barcelona.

Nicol, E. (1990). Formas de hablar sublimes. Poesía y Filosofía. UNAM. México.

Noguera, A.P. (2004). El reencantamiento del mundo. Ideas Filosóficas para la construcción de un Pensamiento Ambiental Contemporáneo: IDEA-UN-PNUMA. Manizales.

Noguera, A.P. (2007). (Compiladora). El paso del sujeto/objeto al bucle red-trama de vida. Disolución de la epistemología moderna y emergencia de la filosofía ambiental. En: Hojas de sol en la victoria Regia. Emergencias de un pensamiento ambiental alternativo en América Latina: Universidad Nacional de Colombia. Manizales.

Noguera, A.P, Pineda, J, Echeverri, J, y otros (2010). Afecto Tierra: Universidad Nacional. Manizales. Inédito.

Pardo, J.L. (1991). Sobre los espacios pintar, escribir, pensar: Ediciones del Serbal. Barcelona.

Pardo, J.L. (2004). La intimidad: Pre-Textos.Valencia.

Pineda, J. (2004). Relatar, narrar y fabular los modos del habitar ecopoético. En: Luna azul. ucaldas. edu.co. Manizales.

Pineda, J. (2009). Geopoética del Habitar (Tesis inédita de maestría). Universidad de Caldas. Manizales.

Serres, M. (2003). Los cinco sentidos. Ciencia, poesía y filosofía del cuerpo: Taurus. Bogotá.

Taylor, P. (2005). La ética del respeto a la naturaleza: Cuadernos de crítica. UNAM-Instituto de investigaciones filosóficas. México.

Torres, M. (1996). La dimensión ambiental: un reto para la educación de la nueva sociedad. Proyectos ambientales escolares PRAE. Una estrategia para la inclusión de la dimensión ambiental en la escuela: Serie documentos especiales. Ministerio de Educación Nacional. Bogotá.

Yory, C.M. (2007). Topofilia o la dimensión poética del habitar: Editorial Pontificia Universidad Javeriana. Bogotá.

Zapata, J. (2006). Educación poiética: digno derecho del género humano. Límite, vol. 1, número 013: Universidad de Tarapacá. Chile. 